\title{
Experimental methods in proofs
}

Gabriele Lolli

Dept. of Mathematics, University of Torino, Italy

The presence of experimental methods in mathematics has been the leit-motiv of the so called, by Imre Lakatos in [12], renaissance of empiricism in the philosophy of mathematics.

Among the efforts of reviving the philosophy of mathematics, as urged by Reuben Hersh in [9], in the Seventies the empiricist trend was the most vociferous and fashionable. It could rely on, and was enhanced by the novelties introduced by the computer, namely much larger searches and the formation of conjectures, either by numerical computations or by computer graphics. But as a thesis on the nature of mathematics it had to find confirmation and roots in the history of mathematics.

Prominent among others were Hilary Putnam [14] and Imre Lakatos [11]; they didn't rescue from oblivion old philosophies claiming the empirical nature or origin of mathematical objects; they proposed the term "quasi-empirical" to characterize non-deductive methods of discovery and validation in mathematics. The term was taken from Euler, via Polya.

It had actually been George Polya, in [13, pp. 17-22], some twenty years before to stress the importance of the heuristic non-deductive moment in the search for a proof, and to call attention to Euler's unorthodox methods. The same Eulerian examples were quoted by Putnam and by Mark Steiner in [16].

Empirical methods are loosely meant by the empiricists, with differences among them, to be procedures of discovery and validation which are similar to those of the natural sciences.

By "quasi-empirical" methods I mean methods that are analogous to the methods of the physical sciences, except that the singular statements which are "generalized by induction", used to test "theories", etc., are themselves the product of proof or calculations rather than being "observation reports" in the usual sense [14, pp. 49-65].

The reminder of the presence of such procedures has been beneficial to the philosophy of mathematics. The purpose of this essay however is to give 
elements, through the analysis of a few examples, to dismantle the often connected thesis that mathematics should thereby forego its pretension to a unique position among sciences. If the "statements used to test theories" are themselves mathematical, the similarity is limited to the forms of argumentation. But the fact that mathematicians use many strategies and various instruments to attack a problem does not mean that the solutions, when found, are not rooted in a deductive setting: they purport to be logical consequences of the data and of the formal specification of the notions involved. If not, they are sooner or later recognized defective, and the search goes on, aiming at a finer or deeper analysis ${ }^{1}$

There are many degrees of involvement of empirical methods in mathematics.

The first, more widespread and less interesting, is that of inductive formation of conjectures through observations.

The second is the presence of empirical facts or elements in the very body of an argument proposed as a proof.

The strongest is represented by proofs found by machines, but it has in a way turned topsy-turvy, since the formal proofs thus produced are pure logic, the opposite of a liberated notion of proof.

Given its many facets, we will not dwell on this last topic, which began to be discussed with Tymoczko's remarks on the Four-Color Theorem ${ }^{2}$ and is revived with every new computer performance ${ }^{3}$.

\subsection{Euler's observations}

Let us have a look at Euler's paper [4] quoted by Polya, "Specimen de usu observationum in mathesi pura", where he says that many notable properties are first observed and worked upon before being proved.

Inter tot insignes numerorum proprietates, quae adhunc sunt inventae ac demonstratae, nullum est dubium, quin pleraeque primum ab inventoribus tantum sunt observatae et in multiplici numerorum tractatione animadversae, antequam de iis demonstrandis cogitaverint ${ }^{4}$.

A fuller presentation is in the summary ${ }^{5}$ :

\footnotetext{
${ }^{1}$ The author is grateful to a careful and subtle referee for many corrections; not all of her suggestions for improvements could be met in such a short and unpretentious essay.

${ }^{2}$ See [19], [17], [18], [2].

${ }^{3}$ Such as the non-existence of a projective plane of order 10, the sphere packaging problem, the Robbins conjecture. See [6], [1].

4 "Among so many notable properties of numbers, which up to now have been found and proved, there is no doubt that many have been observed and worked upon by their discoverers well before they thought of a proof thereof".

5 "Summarium", in [4, pp. 459-60]. We quote from the Opera omnia edition. Italics added.
} 
Haud parum paradoxum videbitur etiam in Matheseos parte, quae pura vocari solet, multum observationibus tribui, quae vulgo nonnisi in obiectis externis sensus nostros afficientibus locum habere videntur. Cum igitur numeri per se unice ad intellectum purum referri debeant, quid observationes et quasi experimenta in eorum natura exploranda valeant, vix perspicere licet. Interim tamen hic solidissimis rationibus ostensum est plerasque nomerorum proprietates, quas quidem adhux agnovimus, primum per solas observationes nobis innotuisse, idque plerumque multo antequam veritatem earum rigidis demostrationibus confermaverimus. Quin etiam adhuc multae numerorum proprietates nobis sunt cognitae, quas tamen nondum demonstrare valemus; ad earum igitur cognitionem solis observationibus sumus perducti. Ex quo perspicuum est in scientia numerorum, quae etiamnunc maxime est imperfecta, plurimum ad observationibus esse expectandum, quippe quibus ad novas proprietates numerorum continuo deducimur, in quarum demonstratione deinceps sit elaborandum. Talis cognitio solis observationibus innixa, quandiu quidem demonstratione destituitur, a veritate sollicite est discernenda atque ad inductionem referri solet. Non desunt autem exempla, quibus inductio sola in errores praecipitaverit. Quascumque ergo numerorum proprietates per observationes cognoverimus, quae idcirco sola inductione innituntur, probe quidem cavendum est, ne eas pro veris habeamus, sed ex hoc ipso occasionem nanciscimur eas accuratius explorandi earumque vel veritatem vel falsitatem ostendendi, quorum utrumque utilitate non caret $^{6}$.

In this research Euler wants to characterize the numbers which can be written as $2 a a+b b, a$ and $b$ relatively prime. Similar questions arise in con-

\footnotetext{
6 "It is not a little paradox that in the part of mathematics which is usually called pure so much depends on observations, which people think to have to do only with external objects affecting our senses. Since numbers in themselves must refer uniquely to pure intellect, it i does not seem worth investigating the value of observations and quasi experiments in their study. However it can be shown with strong reasons that the greatest part of the properties of numbers we have come to know have been noted at first only through observations, long before their truth has been confirmed by strict proofs. And there are even many of them which we know but we are not yet able to prove: we have come to their knowledge only through observations. So it is clear that in the science of numbers, which is still greatly incomplete, a lot has to be expected from observations, to find new properties of numbers for which later a proof has to be worked out ... Such knowledge depending only on observations, in case a proof is lacking, must be carefully distinguished from truth, and based only on induction. There is no lack of examples in which induction alone has led to errors. Whenever we come to know a property of numbers through observations, based only on induction, beware not to take it as true, but take the opportunity to investigate it carefully and show its truth or falsity, in any case a useful deed".
} 
nection with the study of Pythagorean triples. So Euler lists all such numbers up to 500, and begins to make observations on the table he is considering:

- that if a prime number is there, that is it if it can be written as sum of a square and twice a square, this presentation is unique;

- that if a prime number $n$ can be so written, the same holds for $2 n$;

- that if an odd number can be so written, the same is true for its double, and conversely, for an even number and its half;

- that if two numbers can be so written, the same is true for their product;

- that the prime divisors of such a number are of the same form;

and so on, to arrive through this series of remarks to the fact that

- the prime divisors of such a number, if it has any, are of the form $8 n+1$ or $8 n+3$,

and so on, finally arriving at a proposition affirmed by Fermat, without proof, that

- prime numbers of the form $8 n+1$ or $8 n+3$ can be written as $2 a a+b b$ and they only.

Having arrived at such a conjecture, Euler according to the summary first checks it up to 1000, then proceeds to give a prove of it, through a series of theorems paralleling the observations. Some of the proofs are easy, in Euler's opinion, treading in the very observations steps, some require algebraic arguments, only one is profund and uses the method of infinite descent.

Euler did not underrate proofs. At the beginning of the paper he wrote:

Quamvis autem huiusmodi proprietas per assiduam observationem fuerit animadversa, quae per se menti non parum esse iucunda, tamen, nisi demonstratio solida accrescerit, de eius veritate non satis certi esse possumus; exempla enim non desunt, quibus sola inductio in errorem praecipitaverit. Tum vero ipsa demonstratio non solum omnia dubia tollit, sed etiam naturae numerorum penetralia non mediocriter recludit nostramque numerorum cognitionem continuo magis promovet, a cuis certe doctrinae perfectione adhuc longissime sumus remoti. Verum si cui haec forte non magni momenti esse videantur, quod vix unquam ullum in Mathesi applicata usum habitura putentur, usus, quem inde in ratiocinando adipiscimur, non est contemnendus ${ }^{7}$.

\footnotetext{
7 "Although such property has been controlled by careful observations, to the full satisfaction of our mind, this notwithstanding we cannot be certain of its truth, if some strong proof is not added; there is no lack of examples in which induction alone has led to errors. In fact the proof not only eliminates all doubts, but also illuminates the mysteries of their nature and greatly increases our knowledge of numbers, whose theory is still far from perfect. And if this does not appear of great importance in the uses which are considered relevant in applied mathematics, it must not be underrated the utility we get in reasoning", [4, pp. 461-62].
} 
Proofs do not only eliminate doubts, they illuminate and improve our knowledge.

There are other features of Euler's methods which are attractive to the empiricists, for example the use of analogies (from finite to infinite) in the work on series. But Euler's attitude with respect to their proofs was the same. It is true that he said that his method for finding the sum of the series of the inverses of squares,

$$
\sum_{k=1}^{\infty} \frac{1}{k^{2}}=\frac{\pi^{2}}{6}
$$

which to some could appear not enough reliable, had had a strong confirmation in that he could prove with it a known result of Leibniz (the sum of the alternating series of inverses). So we should not have doubts about other results. But he nevertheless continued to search for a proof, until he found one, as Polya, though not Putnam or Steiner, took care to remind, in [13, p. $21]$.

So it seems out of place the question that continues to be asked ${ }^{8}$, as in [5]: "What shall we say, then? Are we wrong to insist on rigorous proofs? Is there a special category of argument, something less than full proofs, something more than blowing smoke? Or do truly great mathematicians get special dispensation?".

There is nothing to add to Euler's own comments above on the utility and the limits of observations in pure mathematics.

\subsection{Archimedes' mechanical method}

The idea of using mechanical devices to perform operations or graphical representations of curves is very old. Eudoxus and Architas among others used machines to draw higher order curves to solve problems such as the trisection of an angle and the duplication of a cube.

Eudoxus and Archytas had been the first originators of this far-famed and highly prized art of mechanics, which they employed as an elegant illustration of geometrical truth, and as a means of sustaining experimentally, to the satisfaction of the senses, conclusions too intricate for proofs by words and diagrams. In the solution of the problem, so often required in constructing geometrical figures, given two extremes, to find the two mean lines of a proportion, both these mathematicians had recourse to the aid of an instrument, adapting to their purpose certain curves and sections of lines.

But what of Plato's indignation at it, and his invective against it as a mere corruption and annihilation of the one good in geometry, which was thus shamefully turning its back upon the unembodied objects

\footnotetext{
${ }^{8}$ Something more will be said in section 3 .
} 
of pure intelligence to recur to sensation, and to ask help (not to be obtained without base supervisions and depravations) from matter; so it was that mechanics came to be separated from geometry, and, repudiated and neglected by philosophers, took place as a military $\operatorname{art}^{9}$.

Fortunately not everybody yielded to Plato's curse. Prohibitions are never welcome in science.

In the dedication of the Method to Eratosthenes, Archimedes ${ }^{10}$ explains that he is going to present the peculiarities of a method which confers a certain easiness to treat mathematical questions with mechanical considerations. He has obtained with this method a few results he has already communicated to Eratosthenes. He wants the method to be known because he is sure that it will be fruitful and produce other results.

Archimedes is convinced that this method will be useful also for the proofs. The results obtained with it do not come with a real proof, but it is easier to look for one when one has acquired a certain familiarity with the matter using the method. He promises that at the end he is going to give geometrical proofs

Then he begins with the first result, namely that the area of a parabolic segment is equal to $4 / 3$ of the inscribed triangle (same base and same height).

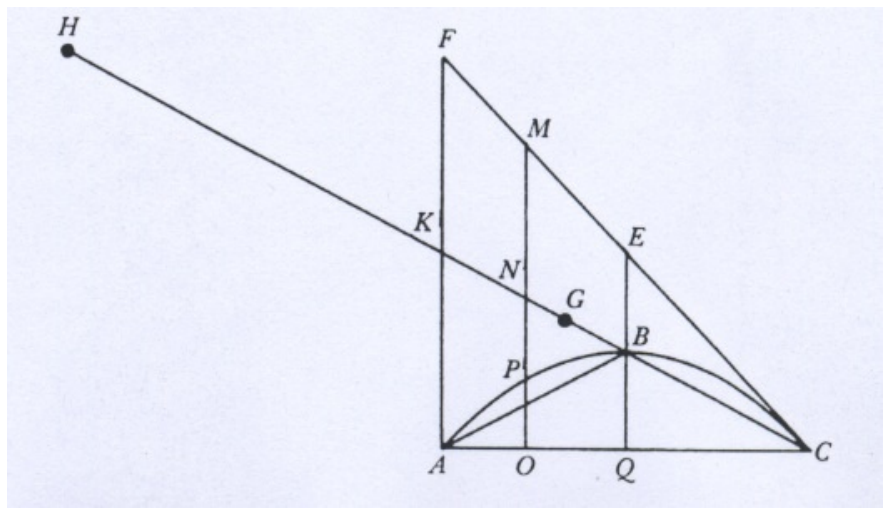

Fig. 1.1. Archimedes' mechanical proof

In the figure 1

- $\mathrm{Q}$ is the midpoint of $\mathrm{AC}$,

- QBE is parallel to the axis of the parabola

\footnotetext{
${ }^{9}$ Plutarch, Life of Marcellus, c 14.5, quoted from [10, p. 146].

${ }^{10}$ An english translation of The Method of Archimedes is published as an appendix to $[7]$.
} 
- AF is parallel to $\mathrm{QBE}$

- $\mathrm{CF}$ is tangent in $\mathrm{C}$

- $\mathrm{HK}=\mathrm{KC}$.

Think of $\mathrm{K}$ as the fulcrum of a scale with arms HK and (the other along) $\mathrm{KC}$.

Let MO be any line parallel to EQ. By known geometric properties

$$
\mathrm{EB}=\mathrm{BQ}, \mathrm{FK}=\mathrm{KA}, \mathrm{MN}=\mathrm{NO}
$$

and moreover

$$
\begin{aligned}
& \mathrm{CA}: \mathrm{AO}=\mathrm{MO}: \mathrm{OP} \\
& \mathrm{CA}: \mathrm{AO}=\mathrm{CK}: \mathrm{KN}
\end{aligned}
$$

hence

$$
\mathrm{HK}: \mathrm{KN}=\mathrm{MO}: \mathrm{OP} .
$$

Now, since $\mathrm{N}$ is the center of gravity of line MO, if we take a segment TS equal to OP and we put TS with its center of gravity in H, THS will balance $\mathrm{MO}$, because $\mathrm{HN}$ is divided by $\mathrm{K}$ in parts which are inversely proportional to the weights TS, MO, that is because

$$
\mathrm{HK}: \mathrm{KN}=\mathrm{MO}: \mathrm{TS},
$$

For the same reason, the other parallels to EQ balance the segments intercepted on them by the parabola, between $\mathrm{A}$ and $\mathrm{C}$, (transported in $\mathrm{H}$ ) so that the sum of the former balances, with respect to $\mathrm{K}$, the sum of the latter.

Now the segments obtained as OP compose the parabolic segment ABC, while the vertical lines drawn in the triangle CFA make the triangle CFA. This, where it is, balances with respect to $\mathrm{K}$, the parabolic segment transferred with its center of gravity in $\mathrm{H}$. If $\mathrm{G}$ is the point of $\mathrm{CK}$ such that

$$
\mathrm{CK}=3 \mathrm{KG}
$$

$\mathrm{G}$ will be the center of gravity of CFA, hence, denoting by sgm.ABC the parabolic segment,

$$
\text { CFA : sgm.ABC in } \mathrm{H}=\mathrm{HK}: \mathrm{GK} \text {. }
$$

But

$$
\mathrm{HK}=3 \mathrm{KG}
$$

from which it follows

$$
\mathrm{CFA}=3 \text { sgm.ABC. }
$$

As

$$
\mathrm{CFA}=4 \mathrm{ABC}
$$

it follows that 


$$
\text { sgm. } \mathrm{ABC}=4 / 3 \mathrm{ABC} .
$$

According to Archimedes the argument above does not prove the result, and this will not do, since "those who boast of many discoveries, without ever giving a proof, sometimes can be caught out, having claimed to have impossible things".

But the argument bestows on the result an appearance of truth. When one rightly suspects the truth, one can more confidently look for a proof, and Archimedes had in fact found it, actually two. In the Quadrature of the Parabola he had first trasformed the argument of the Method based on the infinitesimals in a proof by exaustion. Here ironically he was again in trouble, because the exhaustion method was far from being accepted and he had to expostulate for it. It was based on Eudoxus' (now Archimedes') axiom, or the "lemma": given two unequal areas, it is possible by adding the difference between the two, to surpass any given bounded area. Archimedes is at pain to recall propositions in Euclid's Elements proved by this lemma, and asks for the same reliability to be accorded to his own uses.

But then in the final propositions of the Quadrature, 18-24, he gives a purely geometrical proof ${ }^{11}$.

\subsection{Mathematics in statu nascenti}

We claim that such arguments as constructed with Archimedes' mechanical method are more than heuristic suggestions as to the truth of the statements involved. They could be accepted as conclusive; this is not because empirical methods are allowed in mathematics, but because in fact such arguments, with a grain of liberality, can be considered proofs.

There are no physical operations involved, such as weighing tin plates, though such operations can be and are, or used to be performed in early maths education with children. The whole argument is a thought experiment based on notions which are still imperfectly mathematized, but on their way to become object of mathematical theories.

Archimedes himself contributed to the founding and development of Statics. In On the Equilibrium of Planes and The Centers of Gravity of Planes he laid the principles and the theory of the lever, stating a few postulates, such as $^{12}$ :

- Equal weights at equal distances are in equilibrium, and equal weights at unequal distances are not in equilibrium but incline toward the weight which is at the greatest distance.

- If, when weights at certain distances are in equilibrium, something is added to one of the weights, they are not in equilibrium ...

\footnotetext{
${ }^{11}$ See also Enrico Rufini in [15, pp. 216-19].

12 The following quotations are taken from [3].
} 
- If magnitudes at certain distances are in equilibrium, other magnitudes equal to them will be also in equilibrium at the same distances. $\cdots$

From these the first laws of the lever are then proved, e.g: the first: Weights which balance at equal distances are equal.

Later Greek texts give a definition of the center of gravity:

We say that the center of gravity of any body is a point within the body such that, if the body can be conceived to be suspended from the point, the weight carried thereby remains at rest and preserves the original position.

Archimedes did not refer to such definition, instead again he gave axioms for the center of gravity, such as

- If from a magnitude some other magnitude is subtracted, and if the same point is the center of gravity of the original magnitude and of that subtracted, then that same point is the center of gravity of the remaining magnitude.

- If from a magnitude some other magnitude is subtracted, and if the whole magnitude and the subtracted one do not have the same center of gravity, the center of gravity of the remaining magnitude is found by extending the line joining the two centers of gravity beyond the center of gravity of the original magnitude, and taking on it a segment which has to the segment joining the two centers of gravity the same proportion which holds between the weight of the subtracted magnitude and the weight of the remaining magnitude.

- If the centers of gravity of any number of magnitudes lie on the same line, also the center of gravity of their sum will lie on the same line.

- The center of gravity of a straight line is its middle point.

- The center of gravity of a triangle is the point of intersection of the lines drawn from the vertices to the middle points of the sides,

and other similar, enough to calculate the center of gravity of plane polygonal figures.

Once the theory of momentum and center of mass is fully mathematized, there is no obstacle to vindicate Archimedes' proofs ab omni naevo and to recast them in perfectly acceptable mathematical proofs.

The same can be said for other similar examples. We recall only Lakatos' analysis of Euler's theorem $V-E+F=2$ on polyedra. Lakatos' analysis is too well known, and perhaps obsolete, to dwell on it. The first proof presented in Lakatos' dialogue is inspired by that of Cauchy in 1813 and it is based on the following picture of a polyhedron to which a face has been subtracted and which is flattened on a plane 


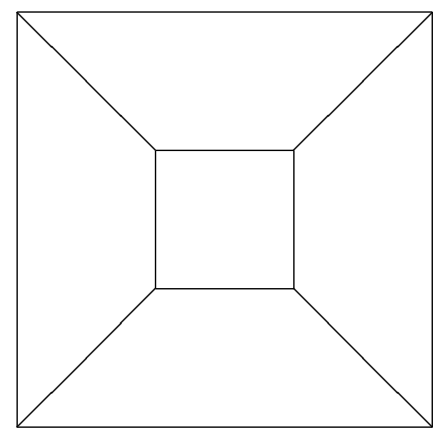

and on a triangulation

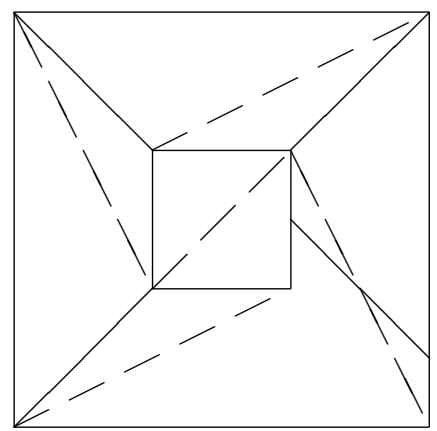

of it. If we cancel a triangle, such as

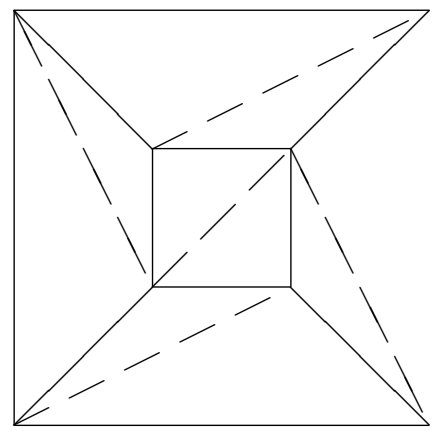

the faces and the edges are reduced by 1 , some different subtraction being realized in the other cases, always preserving the relation $V-E+F=1$. 
We remember only the following crucial remark by Lakatos, relevant for our discussion:

AlPHA: But then we are worse off than before! Instead of one conjecture we now have at least three! And this you call a 'proof'?

...

DeLTA: What does it do then? What do you think a mathematical proof proves?

TEACHER: This is a subtle question which we shall try to answer later. Till then, I propose to retain the time-honoured technical term 'proof' for a thought-experiment - or 'quasi-experiment' - which suggests a decomposition of the original conjecture into subconjectures or lemmas, thus embedding it in a possibly quite distant body of knowledge. Our 'proof', for instance, has embedded the original conjecture - about crystals, or, say, solids - in the theory of rubber sheets [11, p. 9].

To call such a thought-experiment both a proof and a quasi-experiment though linking together these two terms deprives the latter of any meaning. A decomposition of a conjecture into subconjectures is a move quite legitimate and common also in a deductive setting; per se it has nothing to to with the possible distance of the conjured knowledge. Talking of crystals and rubber sheets does not place the discourse outside pure mathematics. The theory of rubber sheets of course is nothing else than what will be called topology.

\subsection{Mechanical devices}

The instruments mentioned in Plutarch's report were however real machines, not just methods inspired by mechanical considerations. Let us recall a few examples.

For the trisection of an angle Nicomedes made use of the conchoid (or cochloid according to Pappus) which was drawn by the contrivance shown in fig. 2.

It was composed of two fixed perpendicular rulers, and one revolving around a peg in $C ; D$ is a fixed peg on $P C$ which can move in the slot in $A B$.

This apparatus was used when one had to insert a segment of given length between two lines one of which was straight. The characteristic property of the conchoid in fact is that the distance $D P$ is constant.

Just as the constructions by ruler and compass have a mathematical equivalent, so it is for this case. The equation of the conchoid is actually in polar coordinates

$$
r=a+b \sec \theta
$$


As Pappus has shown, the solution could be obtained as the intersection of two conics, and from their equations the problem was reduced to the solution of a cubic equation.

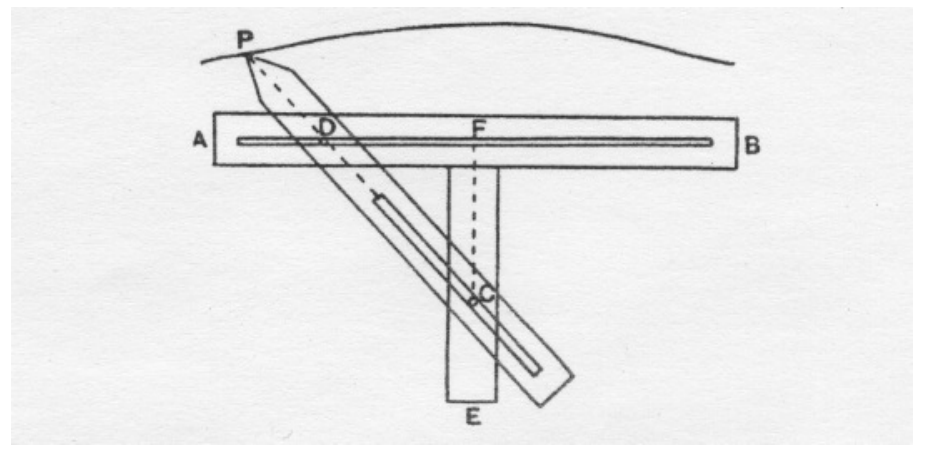

Fig. 1.2. Nicomedes' conchoid

For the trisection of an angle $A \hat{B} C$, with reference to fig. 3, one had to find $E$ on $A F$ parallel to $B C$ and draw $B E$ in such a way that $D E=2 A B$.

With the artifact above, one would then use $B$ for pole, $A C$ for the ruler (the horizontal ruler) and $2 A B$ for the distance.

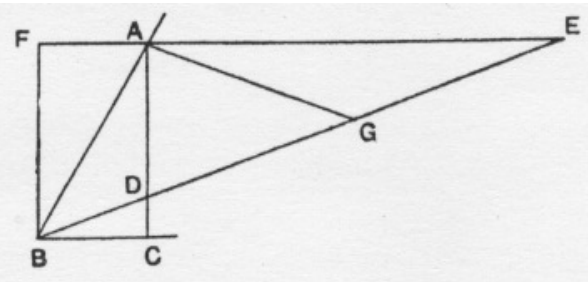

Fig. 1.3. The trisection of $A \hat{B} C$

Ironically, one of these devices, which we are going to consider next, was attributed to Plato ${ }^{13}$.

Hippocrates had shown that the doubling of the cube can be reduced to finding two mean proportionals in continued proportion: if $a: x=x: y=y: b$ then

${ }^{13}$ By Eutocius, but apparently only by him. See the discussion in [8, pp. 255-8]. 


$$
a^{3}: x^{3}=a: b \text {. }
$$

Menaechmus had discovered that since

$$
x^{2}=a y, y^{2}=b x, x y=a b
$$

and these curves exist, as section of right circular cones, one had to find the point $P$ of intersection of the two conics shown in fig. 4 , and its coordinates.

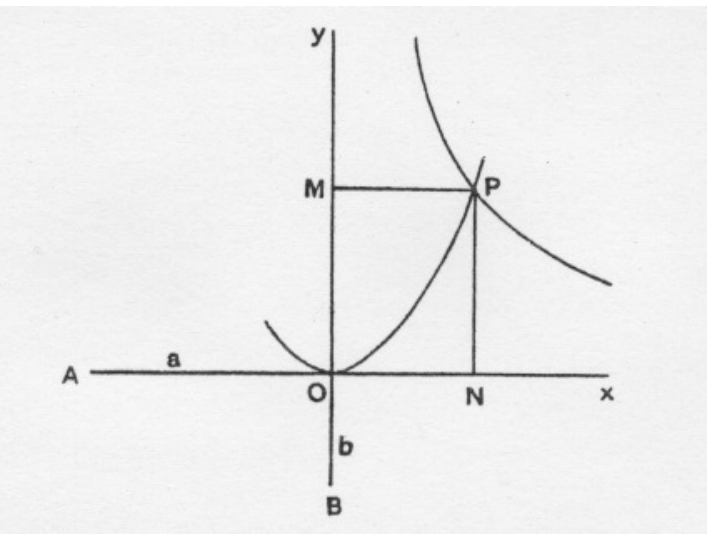

Fig. 1.4. Two mean proportionals between $A O$ and $O B$

For the solution, one could use the device shown in fig. 5 .

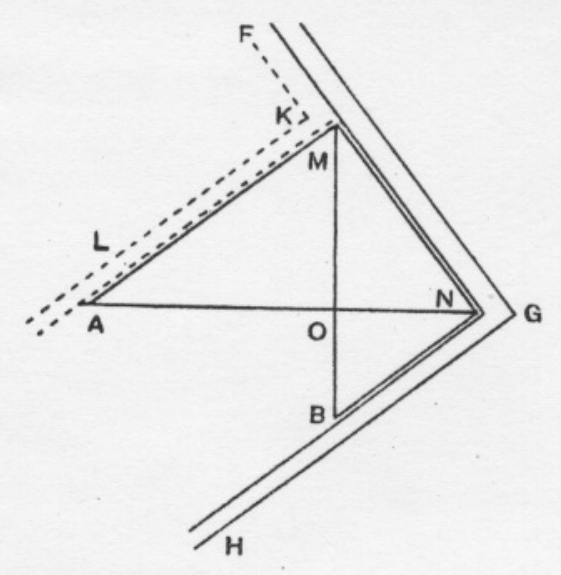

Fig. 1.5. Plato's alleged instrument 
$F G H$ is a rigid right angle, and $F K L$ another one which slides along $G F$ so that $K L$ is always parallel to $G H$. It is positioned so that $G H$ passes through $B$ and it is rotated until the vertex $G$ lies on the prolongation of $A O$. Then one slides $F K L$ until $K L$ passes through $A$. If $K$ is not on $B O$ the device has to be repositioned again with $G$ on $A O$ until the desired configuration shown in picture is reached.

Greek mathematical machines are a fascinating argument, which would be worth pursuing, but what we have said so far should be sufficient for a general provisional conclusion: that if we carefully look at the cases which are known, the mystery about the unholy wedding of experimental methods and mathematical proofs disappears. Or: much ado about nothing. These examples show that mathematics is not, contrary to the empiricists' contention, contaminated by empirical procedures, but that it grows by absorbing and symbolically transforming the physical experience in formal models.

\section{References}

[1] B. Cipra, What's Happening in the Mathematical Sciences, vol. 1 (1993), vol. 2 (1994), vol. 3 (1995-6), vol. 4 (1998-9), Providence, R.I., AMS.

[2] M. Detlefsen e M. Luker, "The Four-Color Theorem and Mathematical Proof", The Journal of Philosophy, 77 (1980), pp. 803-20.

[3] E. J. Dijksterhuis, Archimedes, Princeton University Press, Princeton, 1987.

[4] Leonhard Euler, "Specimen de usu observationum in mathesi pura", Novi commentarii academiae scientiarum Petropolitanae, 6 (1756-7), 1761, pp. 185-230, with a summary ibidem, pp. 19-21, both in Opera omnia, ser. I, vol. 2, Commentationes arithmeticae, Teubner, Leizig, 1915, pp. 459-92.

[5] F. Q. Gouvêa, "Euler's Convincing Non-Proofs", Focus, 27, n. 1, 2007, pp. $10-1$.

[6] Th. C. Hales, "Cannonballs and Honeycombs", Notices AMS, 47, 2000, n. 4, pp. $440-9$.

[7] Thomas Heath, The Works of Archimedes, Dover, New York, 1953.

[8] Thomas Heath, A History of Greek Mathematics (1921), vol. 1, Dover, New York, 1981.

[9] R. Hersh, "Some Proposals for Reviving the Philosophy of Mathematics", Advances in Mathematics, 31, 1979, pp. 31-50, reprinted in [20, pp. 9-28].

[10] M. Kac and S. M. Ulam, Mathematics and Logic (1968), Penguin Books, 1979.

[11] I. Lakatos, Proofs and Refutations, Cambridge, Cambridge Univ. Press, 1976, previously published in four parts in The British Journal for the Philosophy of Science, 14, 1963-64.

[12] I. Lakatos, "A Renaissance of Empiricism in the Recent Philosophy of Mathematics", in Philosophical Papers, 2 voll., Cambridge Univ. Press, Cambridge, 1978, reprinted in [20, pp. 29-48].

[13] G. Polya, Mathematics and Plausible Reasoning, vol. 1: Induction and Analogy in Mathematics, Princeton Univ. Press, Princeton, 1954.

[14] H. Putnam, "What is Mathematical Truth", in Philosophical Papers, vol. 1, Mathematics, Matter and Method, Cambridge Univ. Press, Cambridge, 1975, reprinted in [20, pp. 49-65]. 
[15] E. Rufini, Il "Metodo" di Archimede, Zanichelli, Bologna, 1926 (Feltrinelli, Milano, 1961).

[16] M. Steiner, Mathematical Knowledge, Cornell Univ. Press, Ithaca, 1975.

[17] E.R. Swart, "The Philosophical Implications of the Four-Color Problem", Amer. Math. Monthly, 87 (1980), pp. 697-707.

[18] P. Teller, "Computer Proof", The Journal of Philosophy, 77 (1980), pp. 797803.

[19] T. Tymoczko, "The Four-Color Problem and Its Philosophical Significance", The Journal of Philosophy, 76 (1979), pp. 57-83.

[20] T. Tymoczko (ed.), New Directions in the Philosophy of Mathematics, Princeton Univ. Press, Princeton, 1998. 